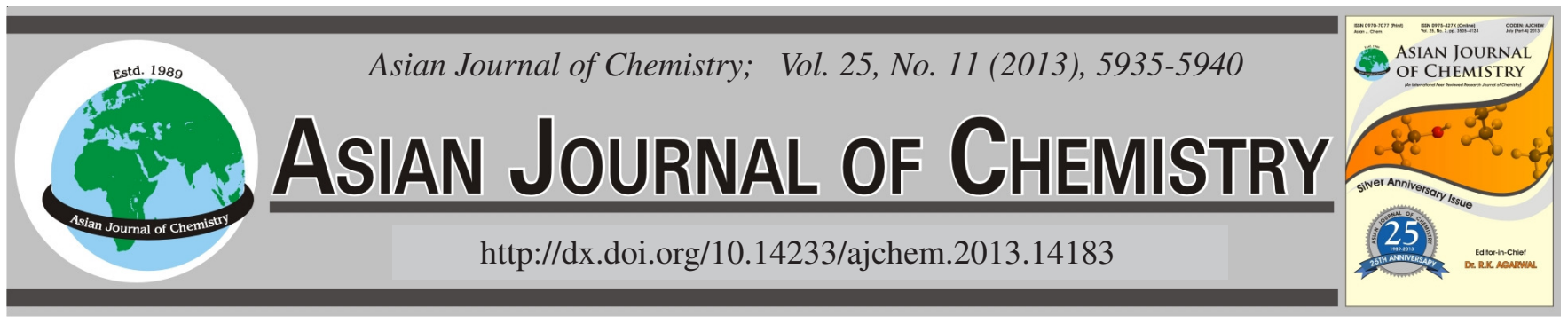

\title{
Preparation and Characterization of Acrylic Acid-Ca-Montmorillonite and \\ Its Application for Preparation of Poly(vinyl acetate)/Montmorillonite Nanocomposite Emulsion by in situ Emulsion Polymerization
}

\begin{abstract}
J. WANG ${ }^{1,2}$ and Z.Y. LiU ${ }^{1,2, *}$
${ }^{1}$ College of Chemistry \& Chemical Engineering, Shihezi University, Shihezi 832003, Xinjiang Province, P.R. China

${ }^{2}$ Xinjiang Bingtuan Key Laboratory for Green Processing of Chemical Engineering, Shihezi 832003, Xinjiang Province, P.R. China

*Corresponding author: Tel: +86 993 2057303; E-mail: lzyongclin@ sina.com

(Received: 7 June 2012;

Accepted: 20 April 2013)

AJC-13371

The materials of acrylic acid-Ca-montmorillonite were synthesized by dehydration reaction between the ethanol/cyclohexane mixed solvent of the reactants of acrylic acid and the cyclohexane solution of alkaline calcium base montmorillonite (acid-activated montmorillonite, calcium oxide and deionized water). The hybrids were characterized by fourier transformation infrared spectroscopy (FT-IR), wide angle X-ray powder diffraction (WXRD), thermogravimetric (TG) analysis. FT-IR analysis showed carboxyl group (-COOH) of acrylic acid reacted with hydroxyl group $(-\mathrm{OH})$ of Ca-montmorillonite. WXRD analysis showed that acrylic acid intercalated the montmorillonite and the basal spacing increased from $1.39 \mathrm{~nm}$ of acid-activated montmorillonite to $1.6 \mathrm{~nm}$ of acrylic acid-Ca-montmorillonite. Thermogravimetric analysis showed that the thermal stability of organo-montmorillonite enhanced. Influences of synthetic parameters in the experiment were studied in detail. According to single factor analysis of synthetic parameters, the optimum preparation conditions was $5 \mathrm{~g}$ Ca-montmorillonite, $5 \mathrm{~g}$ acrylic acid, $50 \mathrm{~mL}$ hexamethylene as dispersing agent, $60 \mathrm{~mL}$ ethanol/hexamethylene solution (8:52, volume ratio), reaction time 3 $\mathrm{h}$, stirring rate $150 \mathrm{r} / \mathrm{min}$. The poly(vinyl acetate)/montmorillonite nanocomposite emulsion was prepared by in site intercalative emulsion polymerization of vinyl acetate in the presence of organo-montmorillonite. The wide angle X-ray powder diffraction results demonstrated that the montmorillonite was exfoliated during polymerization. The bonding power of the nanocomposite emulsion of containing $3 \%$ organo-montmorillonite was the best one.
\end{abstract}

Key Words: Montmorillonite, Organo-montmorillonite, Acrylic acid-Ca-montmorillonite, Nanocomposite emulsion.

\section{INTRODUCTION}

Montmorillonite (MMT) is useful clay because of its high cation exchange capacity, swelling capacity, high surface areas and strong adsorption ${ }^{1,2}$. It is widely use for various industrial applications such as rheological additives, coating, glues, drilling fluids, cosmetics, pesticide and for wastewater treatment ${ }^{3,4}$. Organically modified montmorillonite have also been widely studied in practical applications in the area of organic-inorganic composites 5 . Since the Toyota group reported that nylon-6/ silicate nanocomposites, polymer-clay nanocomposites have been of great interest for both academic researchers and industrial applications ${ }^{6,7}$. The organic modification of montmorillonite can decrease surface energy of montmorillonite to make it compatible with polymers.

Cation exchange reaction is a traditional, effective way to organic modification of montmorillonite. These inorganic ions in the interlayer of montmorillonite are replaced with organic cationic surfactant molecules which intercalate the clay gallery. The used cationic surfactants include alkylammonium and alkylphosphonium cations ${ }^{8-12}$. Akelah and Moet $^{13}$ have prepared vinyl monomer-montmorillonite by a cation exchange process by the interaction between $\mathrm{Na}^{+}$or $\mathrm{Ca}^{2+}$ cations of montmorillonite and vinylbenzyl trimethylammomium chloride. They have also prepared polystyrene-montmorillonite nanocomposites by free-radical solution of polymerization. Sedláková et al. ${ }^{14}$ have used modification cationic agent [2(acryloyloxy)ethyl]trimethylammonium chloride, which's head formed an ionic bond with montmorillonite and the reactive tail-vinyl group allowed anchoring of polymer onto montmorillonite and formation of polymer(butyl methacrylate)/montmorillonite nanocomposite emulsion. But interaction of surfactants and montmorillonite is weak and the hybrids are unstable. That limits application of montmorillonite. So organic and inorganic segments are linked by stable chemical bond, which is a research hot point in recent years. Chemical bond may enhance organic and inorganic interface forces and produce some special structures and properties. Wei et al..$^{15,16}$ 
prepared alkaline calcium base montmorillonite with anion exchange. The preparation of alkaline calcium base montmorillonite was as follows: Acid-activated montmorillonite mixed with calcium oxide under the existence of water. Calcium oxide reacted with water to obtain calcium hydroxide. When calcium hydroxide diffused into interlayer of montmorillonite, one of the two hydroxyl groups of calcium hydroxide reacted with carboxyl of acid-activated montmorillonite and obtained the alkaline calcium montmorillonite with a hydroxyl. Alkaline calcium montmorillonite can reacts with other organic acids. But they only use saturated acid to modify montmorillonite, such as stearic acid, gluconic acid and benzoic acid ${ }^{17-19}$. We attempt to use organic acids with double bonds to modify alkaline calcium base montmorillonite. The organic acids formed ionic bond with a clay platelet and the terminal reactive vinyl group. These organically modified montmorillonite have potential utility in the preparation of polymer nanocomposites and in other possible application. Montmorillonite is modified by acrylic acid because it can easily intercalate montmorillonite as a small molecule.

In this study, acid-activated montmorillonite (H-MMT) of Xiazijie in Xinjiang Uyghur Autonomous Region was modified with calcium hydroxide, obtained the alkaline calcium montmorillonite (Ca-MMT). Then Ca-MMT was modified with acrylic acid and organo-montmorillonite (OMMT) was obtained. At the same time, we discussed the reaction mechanism and influences of synthetic parameters in the experiment on organic content of organo-montmorillonite. We also prepared the poly(vinyl actate)/montmorillonite nanocomposite emulsion in the presence of organo-montmorillonite with different organo-montmorillonite contents $(0,1,2,3,4$ and $5 \%)$ via in site intercalative emulsion polymerization and investigated the properties of nanocomposite emulsion and the influence of different organo-montmorillonite contents on the nanocomposite emulsion.

\section{EXPERIMENTAL}

Acid-activated montmorillonite (H-MMT) was purchased from Xinjiang Xiazijie Bentonite Co.Ltd. (Xinjiang, China) with active degree $22 \mathrm{mLNaOH}(0.1 \mathrm{~mol} / \mathrm{L}) / 100 \mathrm{~g}$ clay. Calcium oxide was purchased from Shanghai Guange Shiye Co. Ltd.(Shanghai, China). Cyclohexane was purchased from Tianjin Fuyu fine chemical engineering institute (Tianjin, China). Acrylic acid was purchased from Chengdu Kelong chemical reagents factory (Chengdu, China). Absolute ethanol was purchased from Xian chemical reagents factory (Xian, China). Alcohol and ammonium persulfate was purchased from Xian chemical reagents factory (Xian, China). Vinyl acetate (VAc) and OP emulsifier was purchased from Tianjin Guangfu fine chemical engineering institute (Tianjin, China). Poly(vinyl alcohol)17-99 (PVA) was purchased from Lanzhou Xinxibu vinylon Co.Ltd.(Lanzhou, China). Sodium dodecyl benzene sulfonate (SDBS) was purchased from Tianjin Fuchen chemical reagents factory (Tianjin, China). Dibutyl phthalate was purchased from Taiyuan chemical reagents factory (Taiyuan, China). All of the chemical reagents were AR grade and used without further purification. Deionized water was supplied by Shihezi University.
Preparation of acrylic acid-Ca-montmorillonite: The preparing mechanism of montmorillonite modified with acrylic acid is shown in Fig. 1.

$\mathrm{H}-\mathrm{MMT}+\mathrm{Ca}(\mathrm{OH})_{2} \longrightarrow$ MMT- $\mathrm{Ca}(\mathrm{OH})+\mathrm{H}_{2} \mathrm{O}$
MMT-Ca(OH) $+\mathrm{H}_{2} \mathrm{C}=\underset{\mathrm{H}}{\mathrm{C}-\mathrm{COOH}} \longrightarrow \stackrel{\mathrm{H}}{\mathrm{C}=\mathrm{H}-\mathrm{C}}-\mathrm{C}-\mathrm{Ca}-\mathrm{MMT}$

Fig. 1. Mechanism of montmorillonites modified by acrylic acid

Preparation of MMT-Ca(OH): The starting materials were $1.05 \mathrm{~g} \mathrm{CaO}, 3 \mathrm{~g} \mathrm{H}-\mathrm{MMT}$ and $18 \mathrm{~g}$ deionized water in a diameter $95 \mathrm{~cm}$ watch crystal. The mixtures was stirred uniformly by glass bar and was put into thermostatic drying oven to keep $16 \mathrm{~h}$ at $50{ }^{\circ} \mathrm{C}$. After the reaction finished, the rough product MMT-Ca $(\mathrm{OH})(\mathrm{Ca}-\mathrm{MMT})$ was obtained, filtered under vacuum condition, washed several times with deionized water to remove $\mathrm{Ca}(\mathrm{OH})_{2}$ until the filtrate was neutral and dried at $100{ }^{\circ} \mathrm{C}$ in thermostatic drying oven for $1 \mathrm{~h}$.

Preparation of acrylic acid-Ca-MMT: The prepared $5 \mathrm{~g}$ Ca-MMT and $100 \mathrm{~mL}$ cyclohexane were put into $500 \mathrm{~mL}$ fourneck flask equipped with sampling device, thermometer, reflux condenser, water knockout trap, polytetrafluoroethylene anchor stirrer at $100 \mathrm{rpm}$. After the system was heated to backflow through water bath, $2 \mathrm{~g}$ acrylic acid dissolved in the mixed solvent of $60 \mathrm{~mL}$ ethanol/cyclohexane (8:52, volume ratio) was dropped to flask slowly and reacted for $4 \mathrm{~h}$. After the reaction finished, the rough product acrylic acid-Ca-MMT (AA-Ca-MMT) was obtained, then filtered via vacuum suction filter and washed several times with mixed solvent of ethanol/ cyclohexane to remove unreactive acrylic acid. The product was dried at $100{ }^{\circ} \mathrm{C}$ in thermostatic drying oven for $1 \mathrm{~h}$.

Preparation of emulsion: A certain amount of AA-CaMMT $(0,1,2,3,4$ and $5 \%$ based on vinyl acetate monomer in weight) prepared at optimum preparation conditions was dispersed in the deionized water $(50 \mathrm{~g})$ and was stirred at ambient temperature for $24 \mathrm{~h}$ at $400 \mathrm{rpm}$. In order to make the clay swollen the mixture was sonicated for $15 \mathrm{~min}$ prior to polymerization. The polymerization was carried out in a 250 $\mathrm{mL}$ four-neck flask with sampling device, thermometer, reflux condenser, polytetrafluoroethylene anchor stirrer. The flask was charged with poly(vinyl alcohol) $(3.50 \mathrm{~g})$ and suspending liquid of AA-Ca-MMT in the deionized water. The initial charge was stirred at $400 \mathrm{rpm}$ and heated up to $90^{\circ} \mathrm{C}$, which was kept for $0.5 \mathrm{~h}$ to make poly(vinyl alcohol) dissolved completely. Sodium dodecyl benzene sulfonate $(0.13 \mathrm{~g})$ and OP emulsifier $(0.25 \mathrm{~g})$ were added to the systerm when the temperature descend on to $65^{\circ} \mathrm{C}$ with stirring $5 \mathrm{~min}$. Then vinyl acetate $(1.50 \mathrm{~g})$ and $0.3 \mathrm{~mL}$ ammonium persulfate solution that was ammonium persulfate $(15.00 \mathrm{~g})$ was dissolved in water $(85.00 \mathrm{~g})$ were added to emulsion mixture. while the temperature kept $0.5 \mathrm{~h}$ at $70{ }^{\circ} \mathrm{C}$. After reflux ended, vinyl acetate $(5.10 \mathrm{~g})$ was continued to add to upper polymerization emulsion by dropping funnel in the $1.5 \mathrm{~h}$. During the period, $8 \mathrm{~mL}$ ammonium persulfate solution that ammonium persulfate $(5.00 \mathrm{~g})$ was dissolved in water $(95.00 \mathrm{~g})$ was divided into five copies to add, respectively to the polymerization emulsion. After feeding, the polymerization mixture was allowed to polymerize for another $20 \mathrm{~min}$. Then $5 \% \mathrm{NaHCO}_{3}$ solution 
was added to the flask to adjust the $\mathrm{pH}$ value of the obtained emulsion to 6-7. After the reaction system was finished, it cooled down to the room temperature and dibutyl phthalate $(3.50 \mathrm{~g})$ was added to the system with stirring another $5 \mathrm{~min}$. The final latex was obtained without any post preparative treatments. The emulsion polymerization series recipes are show in Table-1.

\begin{tabular}{|c|c|}
\hline \multicolumn{2}{|c|}{$\begin{array}{c}\text { TABLE-1 } \\
\text { RECIPES IN WEIGHT FOR EMULSION POLYMERIZATION }\end{array}$} \\
\hline Ingredient & Charge (g) \\
\hline Vinyl acetate & 33 \\
\hline Buffer: $\mathrm{NaHCO}_{3}$ & 0.5 \\
\hline Initiator: Ammonium persulfate & 0.2 \\
\hline Deionized water & 60 \\
\hline Nonionic emulsifier: OP emulsifier & 0.25 \\
\hline $\begin{array}{l}\text { Anionic emulsifier: Sodium dodecyl benzene } \\
\text { sulphonate }\end{array}$ & 0.13 \\
\hline Protective colloid: Poly(vinyl alcohol) & 3.5 \\
\hline Plasticizer: Dibutyl phthalate & 3.5 \\
\hline AA-Ca-MMT & $0,1,2,3,4$ and $5 \%$ \\
\hline
\end{tabular}

Fourier-transform infrared spectroscopy analysis: FT-IR was carried out on a Nexus Fourier-transform IR spectrometer (Nicolet, United States of America). Samples were recorded on $\mathrm{KBr}$ pellets in the $4000-400 \mathrm{~cm}^{-1}$.

Wide angle $\mathrm{X}$-ray powder diffraction analysis: The interlayer spacing of samples were, respectively investigated by wide powder angle X-ray diffraction (WAXD), which was a Brukker D8 advance Diffractometer (Germany). The X-ray beam was nickel-filtered $\mathrm{CuK}_{\alpha}$ radiation $(\lambda=0.154056 \mathrm{~nm})$ at a generator voltage $40 \mathrm{KV}$ and a generator current of 40 $\mathrm{mA}$. The range of the diffraction angle was $2 \theta=2-40^{\circ}$ with a scanning rate of $0.1 \%$. The (001) basal spacing of clay was calculated using the Bragg equation: $\mathrm{n} \lambda=2 \mathrm{~d} \sin \theta$, where $\lambda$ is the wavelength of the $X$-ray and $\theta$ was the scattering half angle.

Thermogravimetric analysis: The thermogravimetric (TG) analysis measurements were performed using a model STA 449F3 Jupiter thermal analyzer (Netzsch Gerätebau Gmbh, Germany) and the samples were placed in a platium samplepan and characterized by performing a scan from 40$700{ }^{\circ} \mathrm{C}$ at heating rate of $10{ }^{\circ} \mathrm{C} / \mathrm{min}$ in $\mathrm{N}_{2}$ atmosphere.

Test of organic content of montmorillonite: Organic content of montmorillonite was calculated by mass ignition loss. $2 \mathrm{~g}$ OMMT was burnt for $1 \mathrm{~h}$ in the muffle furnace. After the combustion cooled, it was accurately weighed $\mathrm{W}_{\mathrm{a}} \mathrm{g}$. Then the combustion was going on to burn for $1 \mathrm{~h}$ in the muffle furnace. It was accurately weighed $\mathrm{W}_{\mathrm{b}} \mathrm{g}$ after the residue. Organic content (S) in the sample of the calculation formula is as follows.

$$
\mathrm{S}=\frac{\left(\mathrm{W}_{\mathrm{a}}-\mathrm{W}_{\mathrm{b}}\right)}{\mathrm{W}_{\mathrm{a}}} \times 100 \%
$$

Properties of emulsion: The investigation of properties of emulsion was performed as reported ${ }^{18}$. Bonding power was tested by a model BLD-2005 auto stripping tester made by Jinan Languang electro-mechanical technology Co. Ltd. (Jinan, China).

\section{RESULTS AND DISCUSSION}

FT-IR spectra of MMT and AA-Ca-MMT: According to the mechanism (Fig. 1), H-MMT had $\mathrm{H}^{+}$between interlayers, while calcium hydroxide prepared by calcium oxide and water had hydroxyl. Therefore it should be studied whether there was any reaction between H-MMT and calcium hydroxide. Then acrylic acid was also investigated whether there was any reaction with Ca-MMT with hydroxyl.

The FT-IR results of the modified HMMT, Ca-MMT and AA-Ca-MMT are shown in Fig. 2. In Fig. 2a, the peaks around 3615 and $3420 \mathrm{~cm}^{-1}$ correspond to $-\mathrm{OH}$ stretching vibration of silicate layer and the bond at $1640 \mathrm{~cm}^{-1}$ corresponds to $-\mathrm{OH}$ blending vibration. The sharp peak centered at $1033 \mathrm{~cm}^{-1}$ is associated with the $\mathrm{Si}-\mathrm{O}-\mathrm{Si}$ asymmetry stretching vibration and the peaks at about 915 and $527 \mathrm{~cm}^{-1}$ with the stretching of Al-O, at about $457 \mathrm{~cm}^{-1}$ with the blending of Si-O. In Fig. 2b, the peak at $1433 \mathrm{~cm}^{-1}$ is related to $\mathrm{Ca}^{2+}$ characteristic absorption peak. In Fig. 2c, absorption bands at about 1650 ( $\mathrm{C}=\mathrm{C}$ stretching), $1732 \mathrm{~cm}^{-1}(\mathrm{C}=\mathrm{O}$ stretching $)$ are consequences of acrylic acid. The peaks around $3615 \mathrm{~cm}^{-1}$ correspond to $-\mathrm{OH}$ stretching vibration disappears. That is because that carboxyl (-COOH) of acrylic acid reacted with hydroxyl (-OH) of Ca-MMT.

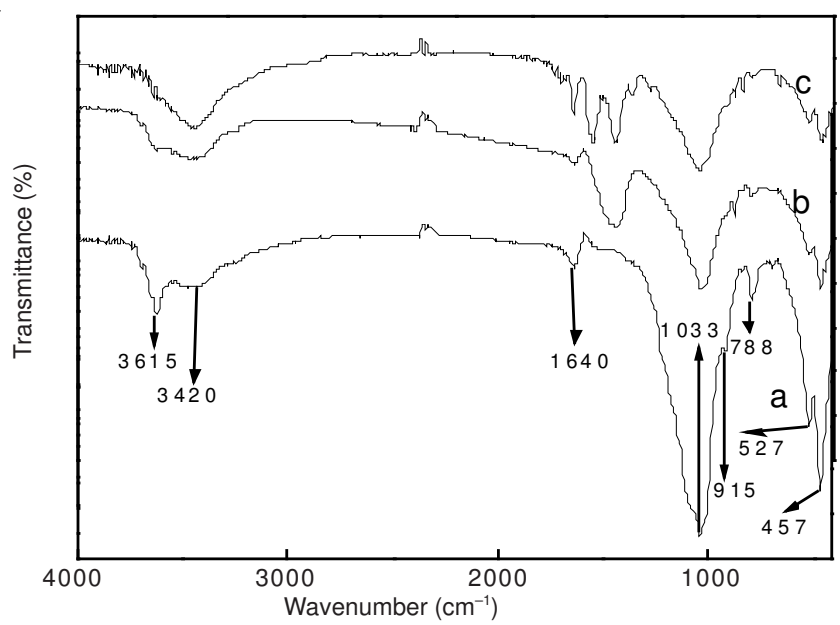

Fig. 2. FT-IR spectra: (a) HMMT, (b) Ca-MMT, (c) AA-Ca-MMT

XRD of MMT and AA-Ca-MMT layers: The WXRD results of H-MMT and the modified H-MMT are shown in Fig. 3. The basal spacing $\left(\mathrm{d}_{(001)}\right)$ for H-MMT is $1.39 \mathrm{~nm}\left(6.3^{\circ}\right.$ peak position in WXRD pattern). After reacted with $\mathrm{Ca}(\mathrm{OH})_{2}$, the intensity of the (001) reflection is still clearly and $\mathrm{d}_{(001)}$ is increased to $1.49 \mathrm{~nm}\left(6.0^{\circ}\right.$ peak position in WXRD pattern). As shown in Fig. 3, the basal spacing of the acrylic acid grafted Ca-MMT, montmorillonite are obviously bigger than that of acid-activated montmorillonite. The basal spacing for OMMT is $1.60 \mathrm{~nm}\left(5.5^{\circ}\right.$ peak position in WXRD pattern). Furthermore, these indicated that $\mathrm{Ca}(\mathrm{OH})_{2}$ and acrylic acid had been intercalated the montmorillonite.

Thermal properties: The TG curves corresponding to H-MMT, Ca-MMT and AA-Ca-MMT are shown in Fig. 4 and the results of the mass loss of H-MMT, Ca-MMT and AA-CaMMT are shown in Table-2. There is a mass loss about $1.52 \%$ in the range of $200-400{ }^{\circ} \mathrm{C}$ for $\mathrm{H}-\mathrm{MMT}$, which is attributed to the mass loss of the bonded water within the gallery. The mass losses between $500-650^{\circ} \mathrm{C}$ for H-MMT is $\mathrm{ca} .1 .91 \%$, which is attributed to the mass loss of dehydroxylation. The structure of Ca-MMT is similar to the H-MMT. However, H-MMT results in larger specific surface area and more available, which 


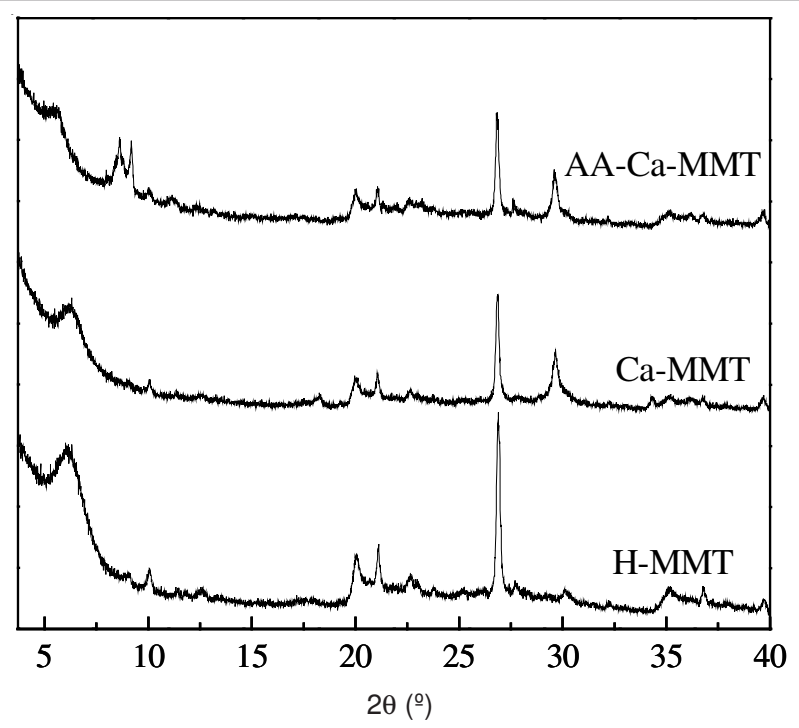

Fig. 3. XRD patterns of H-MMT, Ca-MMT and AA-Ca-MMT

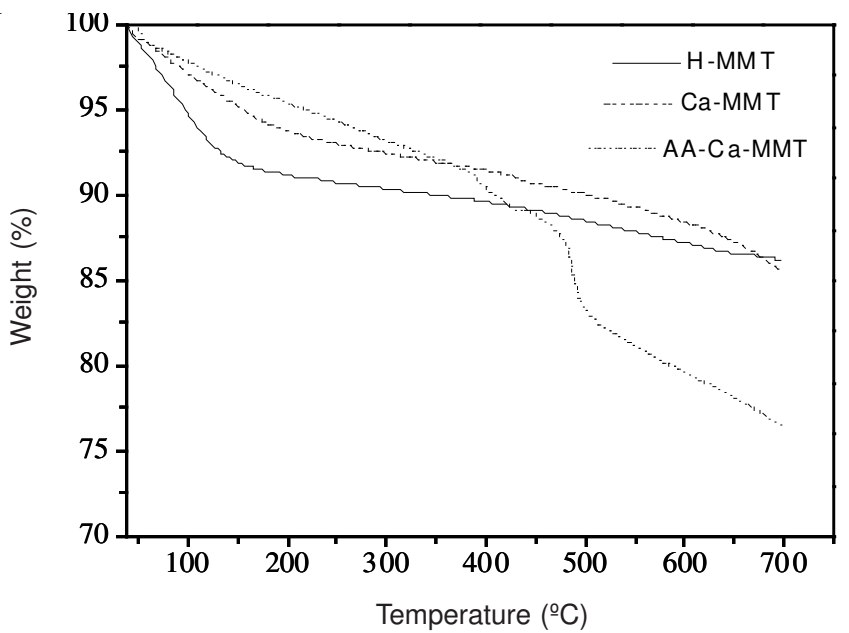

Fig. 4. TG curves of H-MMT, Ca-MMT and AA-Ca-MMT

\begin{tabular}{lcccc} 
TABLE-2 & & & \\
\multicolumn{6}{c}{ MASS LOSS OF H-MMT, Ca-MMT AND AA-Ca-MMT } \\
\hline T $\left({ }^{\circ} \mathrm{C}\right)$ & 179 & 400 & 500 & 700 \\
\hline Mass loss of H-MMT (\%) & 8.56 & 10.40 & 11.53 & 13.74 \\
Mass loss of Ca-MMT (\%) & 5.80 & 8.54 & 9.95 & 14.52 \\
Mass loss of AA-Ca-MMT (\%) & 4.18 & 9.69 & 16.80 & 23.58 \\
\hline
\end{tabular}

can adsorb more amount water than that of Ca-MMT. After $677^{\circ} \mathrm{C}$, the dehydroxylation of $\mathrm{OH}-\mathrm{Ca}^{+}$leads to the more mass loss of Ca-MMT than that of H-MMT. After $426^{\circ} \mathrm{C}$, the mass loss of AA-Ca-MMT decreases sharply, which may is caused by decomposition of acrylic acid that intercalated the clay interlayer.

Influence of acrylic acid on organic content: According preparation of AA-Ca-MMT, the experimental conditions was $5 \mathrm{~g}$ Ca-MMT, $100 \mathrm{~mL}$ dispersing agent hexamethylene, 60 $\mathrm{mL}$ ethanol-hexamethylene solution (8:52, volume ratio), reaction time $4 \mathrm{~h}$, stirring rate $100 \mathrm{rpm}$, investigating influence of acrylic acid on organic content. The result is shown in Fig. 5.

Organic content of montmorillonite increased with increase of the amount of acrylic acid. This was mainly because layered lively hydroxyl (-OH) of Ca-MMT is constant. When the concentration of acrylic acid increased, it made for acrylic

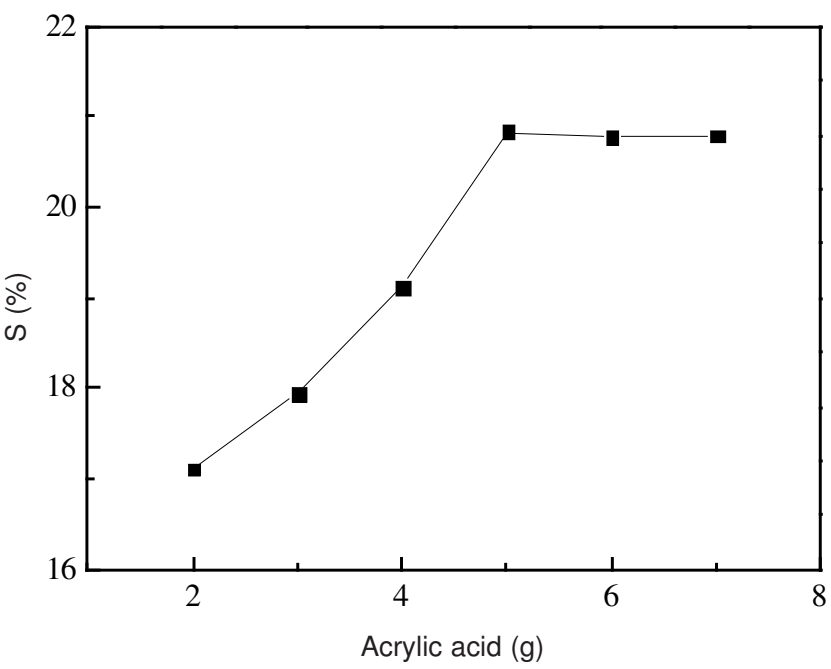

Fig. 5. Influence of acrylic acid on organic content

acid to diffuse into layer of montmorillonite. So carboxyl group $(-\mathrm{COOH})$ reacted with more hydroxyl group $(-\mathrm{OH})$ and generate higher organic content. The best amount of acrylic acid was $5 \mathrm{~g}$.

Influence of hexamethylene on organic content: According to the preparation of AA-Ca-MMT, the experimental condition was $5 \mathrm{~g}$ Ca-MMT, $5 \mathrm{~g}$ acrylic acid, $60 \mathrm{~mL}$ ethanolhexamethylene solution (8:52, volume ratio), stirring rate 100 $\mathrm{rpm}$, reaction time $4 \mathrm{~h}$, investigating influence of hexamethylene on organic content. The results are shown in Fig. 6.

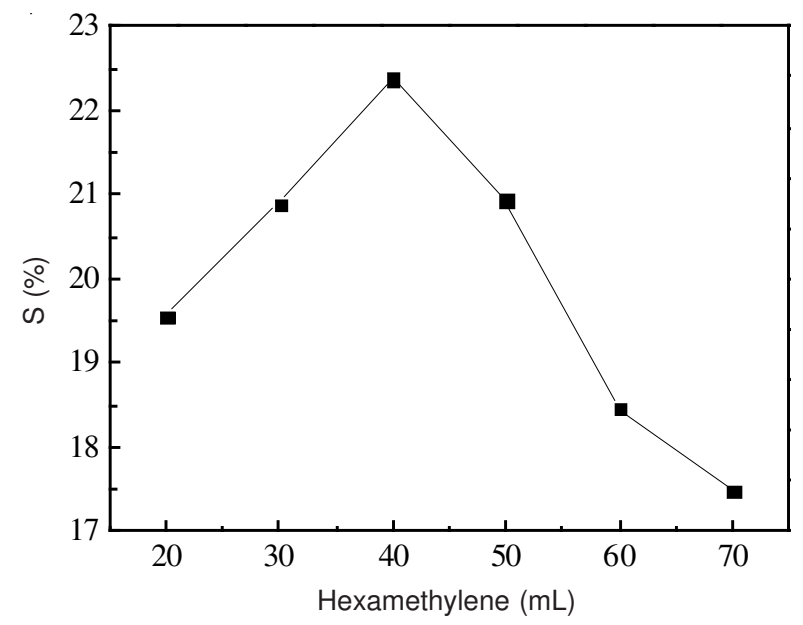

Fig. 6. Influence of hexamethylene on organic content

As the amount of hexamethylene raised, organic content of montmorillonite increased up to maximum value. It may be due to power of mass transfer. As the hexamethylene volume was $40 \mathrm{~mL}$, the montmorillonite was sticky and resistance of acrylic acid transfer increased and was acrylic acid not easy to diffuse into layer of montmorillonite. As hexamethylene volume increased from 70 to $120 \mathrm{~mL}$, the concentration of acrylic acid decreased, power of mass transfer decreased and make organic content decrease. The best amount of hexamethylene was $50 \mathrm{~mL}$.

Influence of ethanol/ hexamethylene volume ratio on organic content: According to the preparation of AA-Ca-MMT, the experimental condition was $5 \mathrm{~g}$ Ca-MMT, $5 \mathrm{~g}$ acrylic acid, 
$50 \mathrm{~mL}$ dispersing agent hexamethylene, stirring rate $100 \mathrm{rpm}$, reaction time $4 \mathrm{~h}$, investigating influence of ethanol and hexamethylene volume ratio on organic content. The results are shown in Fig. 7.

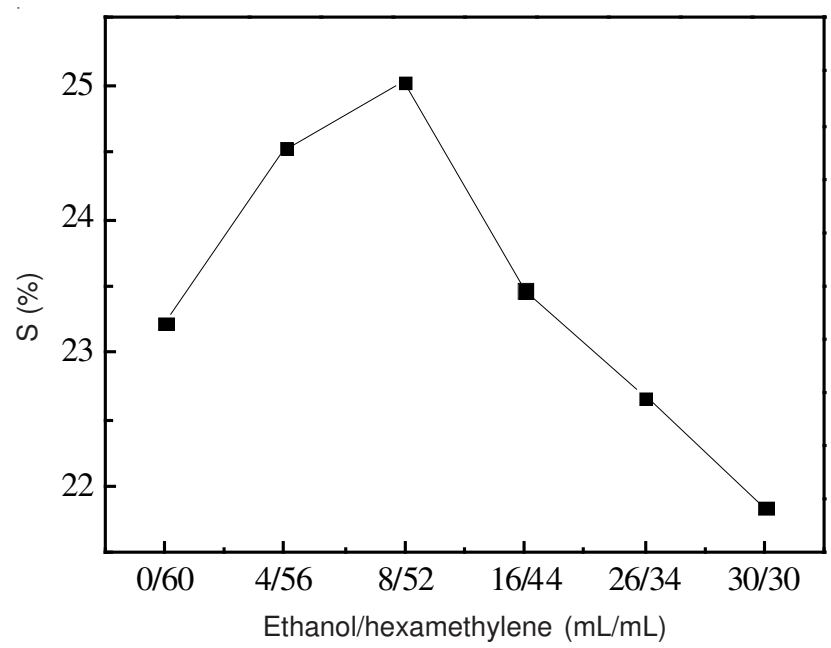

Fig. 7. Influence of ethanol/hexamethylene on organic content

As the ethanol/hexamethylene volume ratio increased the organic content of montmorillonite increased up to maximum value. It may be due to polarity of solution. As the volume ratio was $0 / 60$, acrylic acid was not easy dissoluble with hexamethylene. As the volume ratio increased from 16/44 to $30 / 30$, the ethanol volume increased and polarity of the mixed solution enhanced. However, the dissolubility of acrylic acid in the mixed solution also decreased. Then organic content of montmorillonite decreased. The best ethanol/hexamethylene volume ratio was $8 / 52$.

Influence of reaction time on organic content: According to the preparation of AA-Ca-MMT, the experimental condition was $5 \mathrm{~g}$ Ca-MMT, $5 \mathrm{~g}$ acrylic acid, $50 \mathrm{~mL}$ hexamethylene as dispersing agent, $60 \mathrm{~mL}$ ethanol-hexamethylene solution (8:52, volume ratio), stirring rate $100 \mathrm{rpm}$, investigating influence of reaction time on organic content. The results are shown in Fig. 8.

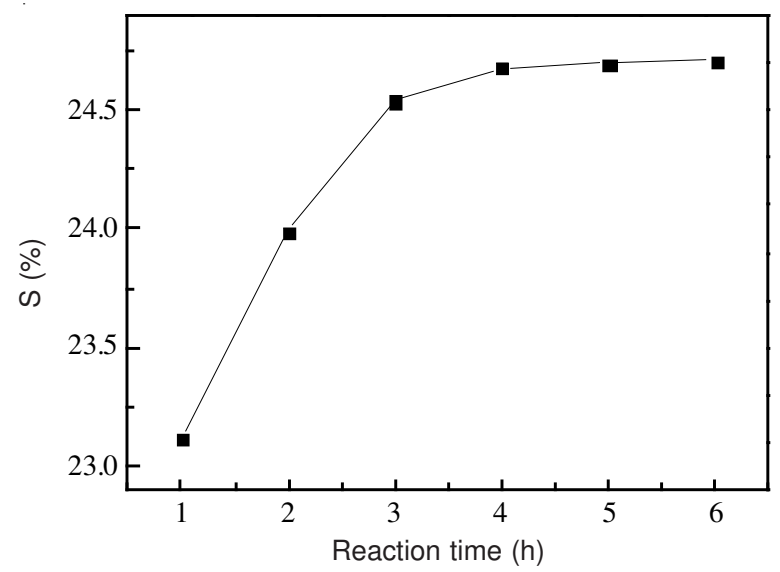

Fig. 8. Influence of reaction time on organic content

As the reaction time increased the organic content of montmorillonite increased. When the reaction time was $3 \mathrm{~h}$, the organic content increased up to maximum value, then not increased. This is mainly because layered hydroxyl $(-\mathrm{OH})$ content of Ca-MMT was certain. Even though the reaction time was prolonged, the organic content didn't greatly change. The optimum reaction time was chosen $3 \mathrm{~h}$.

Influence of stirring rate on organic content: According preparation of AA-Ca-MMT, the experimental condition was $5 \mathrm{~g}$ Ca-MMT, $5 \mathrm{~g}$ acrylic acid, $50 \mathrm{~mL}$ hexamethylene as dispersing agent, $60 \mathrm{~mL}$ ethanol-hexamethylene solution (8:52, volume ratio), reaction time $3 \mathrm{~h}$, investigating influence of stirring rate on organic content. The results are shown in Fig. 9.

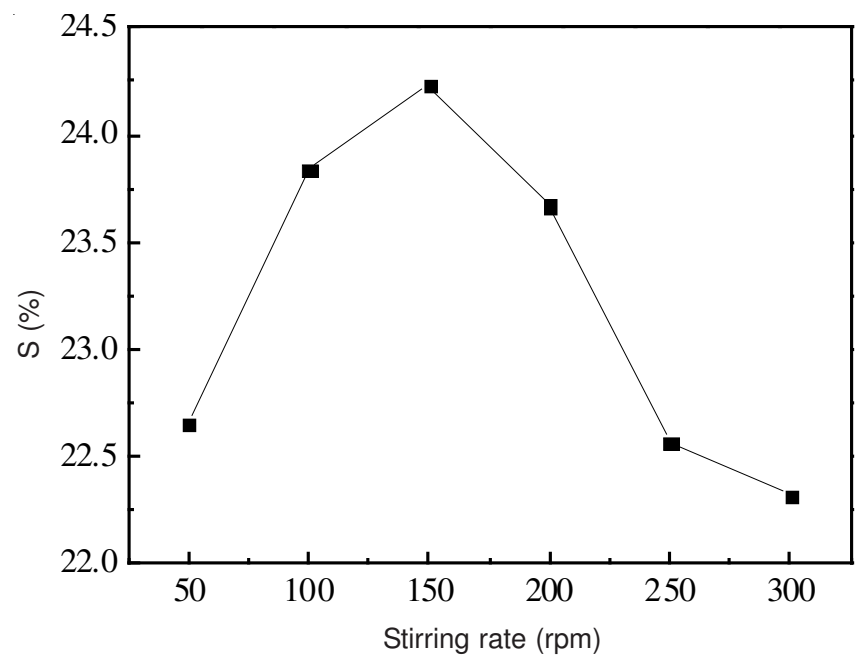

Fig. 9. Influence of stirring rate on organic content

As the stirring rate increased the organic content of montmorillonite increased up to maximum value. When stirring rate was slow, it was not enough power to drive the acrylic acid into the layer of montmorillonite. It leaded to organic degree slowly. When stirring rate was quick, the acrylic acid in the layer of montmorillonite couldn't react, on the contrary it made acrylic acid free out. The best stirring rate was 150 rpm.

WXRD analysis of emulsion: The WXRD patterns of pure poly(vinyl acetate) and composite prepared by vinyl acetate with different amount of OMMT are shown in Fig. 10. No peak corresponding to the (001) plane of MMT can be observed, which means the delamination or the basal spacing of silicates in PVAc/MMT nanocomposites may be increased sharply. In addition of the $\mathrm{d}_{(001)}$ peaks implies that the layered ordered structure of modified MMT was destroyed when the poly (vinyl acetate) chains grew in the layers of modified MMT and exfoliated nanocomposites were formed during the copolymerization.

Properties of emulsion: The basic performances of latex are tested. The results are shown in Table-3. It could be obviously observed that the conversion of vinyl acetate monomer and solid content is decreased with the increasing of MMT nanoparticle adding to the copolymerization system. However, bonding power of the nanocomposite latex of PVAc/ MMT is improved due to strong interaction between silica nanoparticles and polymer matrix via covalent bond. 
TABLE-3

PROPERTIES OF EMULSION

\begin{tabular}{lcccccc}
\hline \multicolumn{1}{c}{ Property } & 0 & $1 \%$ & $2 \%$ & $3 \%$ & $4 \%$ & $5 \%$ \\
\hline Mechanical stability & Yes & Yes & Yes & Yes & No & No \\
Chemical stability & No & No & No & No & No & No \\
Solid content (\%) & 39.80 & 36.14 & 35.94 & 34.22 & 33.45 & 32.36 \\
Adhesive force (N) & 4.11 & 3.02 & 4.50 & 4.65 & 3.89 & 3.84 \\
Conversion (\%) & 98.10 & 86.48 & 85.88 & 80.70 & 78.38 & 74.49 \\
\hline
\end{tabular}

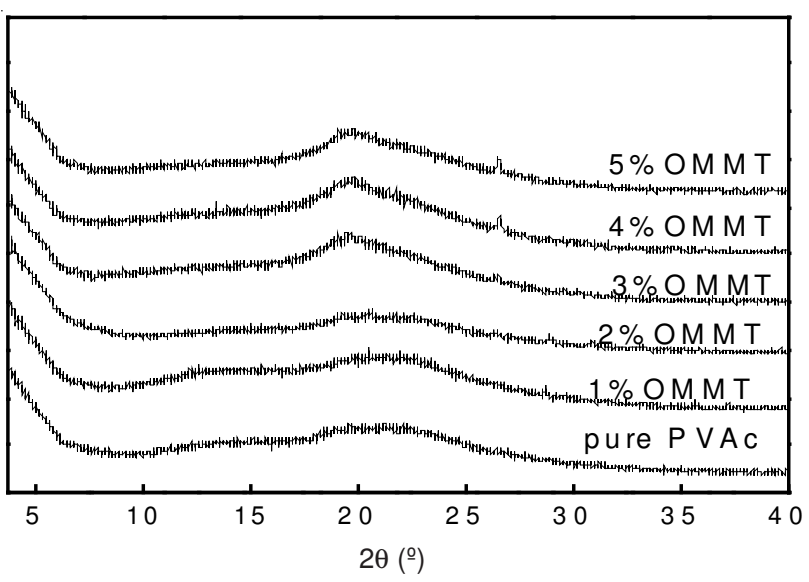

Fig. 10. WXRD patterns of poly(vinyl acetate)/OMMT

\section{Conclusion}

In this study, acrylic acid-Ca-montmorillonite was synthesized using acrylic acid and alkaline calcium base montmorillonite. Unsturated acid-acrylic acid was successfully intercalated into the montmorillonite. According to single factor analysis of synthetic parameters, the optimum preparation conditions was $5 \mathrm{~g}$ Ca-MMT, $5 \mathrm{~g}$ acrylic acid, $50 \mathrm{~mL}$ hexamethylene as dispersing agent, $60 \mathrm{~mL}$ ethanol/hexamethylene solution (8:52, volume ratio), reaction time $3 \mathrm{~h}$, stirring rate $150 \mathrm{rpm}$. The exfoliated PVAc/MMT nanocomposites were prepared by in situ emulsion polymerization of vinyl acetate in the presence of OMMT. The bonding power of the nanocomposite emulsion of containing $3 \%$ OMMT was the best one. The OMMT can not only disperse in polymer well through stable chemical bond between organo-montmorillonite and polymer, but also was exfoliated in polymer matrix. These organically modified montmorillonite have potential utility in the preparation of polymer nanocomposites and in other possible application. It is essential to study organoclays, which improve mechanical and other types properties of nanocomposites.

\section{ACKNOWLEDGEMENTS}

The authors thank Xiazijie Bentonite Co.Ltd. (Xinjiang, China) for providing acid-activated montmorillonite with active degree $22 \mathrm{~mL} \mathrm{NaOH}(0.1 \mathrm{~mol} / \mathrm{L}) / 100$. This work was supported financially by funding from the National Basic Research Program of China (973 Program) (2012CB722603) and Technology-assistance Xinjiang Program (2012AB007).

\section{REFERENCES}

1. C.H. Lee, A.T. Chien, M.H. Yen and K.F. Lin, J. Polym. Res., 15, 331 (2008).

2. A. Salem and L. Karimiz, Korean J. Chem. Eng., 26, 980 (2009).

3. R.R. Tiwari, K.C. Khilar and U. Natarajan, Appl. Clay Sci., 3, 203 (2008).

4. H.A. Patel, R.S. Somani, H.C. Bajaj and R.V. Jasra, Bull. Mater. Sci., 29, 133 (2006).

5. D.R. Paul and L.M. Robeson, Polymer, 49, 3187 (2008).

6. R. Krishnamoorti, R.A. Vaia and E.P. Giannelis, Chem. Mater., 8, 1728 (1996).

7. Y.S. Choi, K.H. Wang, M.Z. Xu and I.J. Chung, Chem. Mater., 14, 2936 (2002).

8. J.P. Zheng, J.X. Wang, S. Gao, and K.D. Yao, J. Mater. Sci., 40, 4687 (2005).

9. O. Yilmaz, C.N. Cheaburu, D. Durraccio, G. Gulumser and C. Vasile, Appl. Clay Sci., 49, 288 (2010).

10. S.S. Ray and M. Okamoto, Prog. Polym. Sci., 28, 1539 (2003).

11. M.Z. Xu, Y.S. Choi, Y.K. Kim, K.H. Wang and I.J. Chung, Polymer, 44, 6387 (2003).

12. P. Èapková, M. Pospíšil, J. M. Brendlé, M. Trchová1, Z. Weiss and R.L. Dred, J. Mol. Model, 6, 600 (2000).

13. A. Akelah and A. Moet, J. Mater. Sci., 31, 3589 (1996).

14. Z. Sedláková, J. Pleštil, J. Baldrian, M. Šlouf and P. Holub, Polym. Bull., 63, 365 (2009).

15. T.Y. Wei, Z.F. Tong and X. Wu, Chinese Patent, 200,510,101,332 (2005).

16. T.Y. Wei, Z.F. Tong, Q. Li, H.H. Fu, C.X. Gao and C.D. Huang, Chinese Patent, 200,710,027,154 (2007).

17. C.X. Gao, T.Y. Wei, D.Q. Li and Z.F. Tong, J. Beijing Univ. Cham. Technol. (Nat. Sci.), 36, 68 (2009).

18. H.J. Li, C.D. Huang, T.Y. Wei and Z.F. Tong, Liquor-Making Sci. Technol., 176, 17 (2009).

19. Z.W Sun, S.H. Xu, G.L. Dai, Y.M. Li, L.R. Lou and Q.S. Liu, J. Chem. Phys., 22, 2399 (2003). 